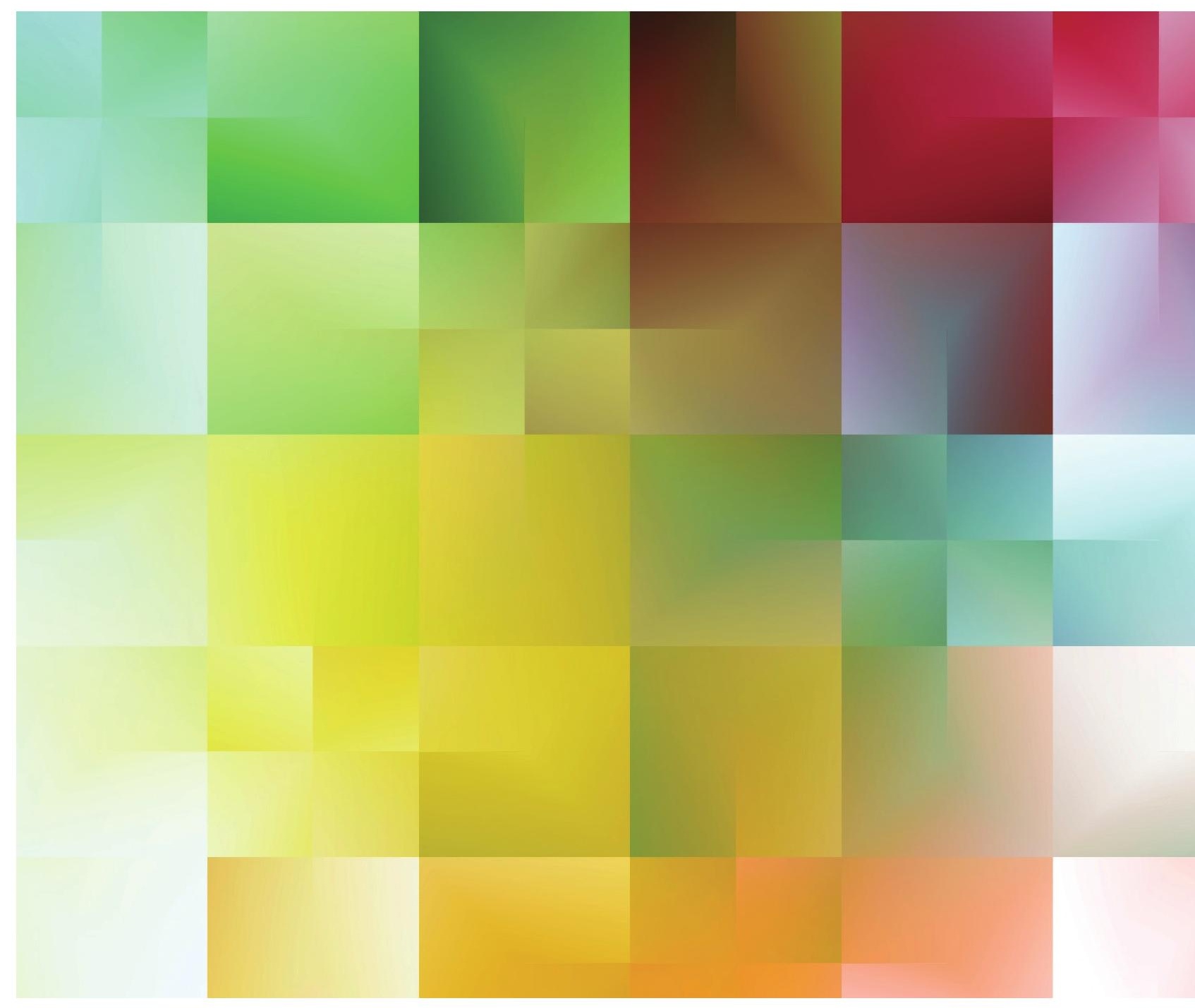

B. Tec. Senac, Rio de Janeiro, v. 39, n.2, p.48-67, maio/ago. 2013. 

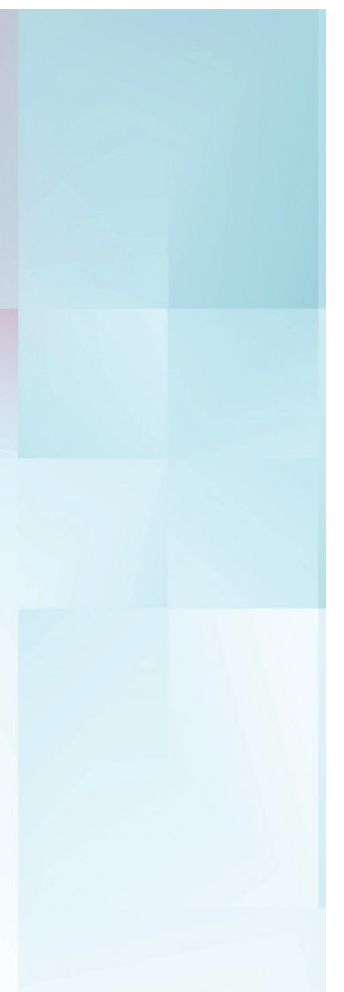

* Doutor em Ciência da Computação (UFMG), professor da Escola de Educação Básica e Profissional da Universidade Federal de Minas Gerais (Coltec/UFMG). E-mail: eduardo@tecnologiadeprojetos.com.br

** Doutor em Educação (USP), professor do Centro Federal de Educação Tecnológica de Minas Gerais (Cefet/MG).

E-mail: dacio@tecnologiadeprojetos.com.br

Recebido para publicação em: 15.10.2012

Aprovado em: 28.06.2013

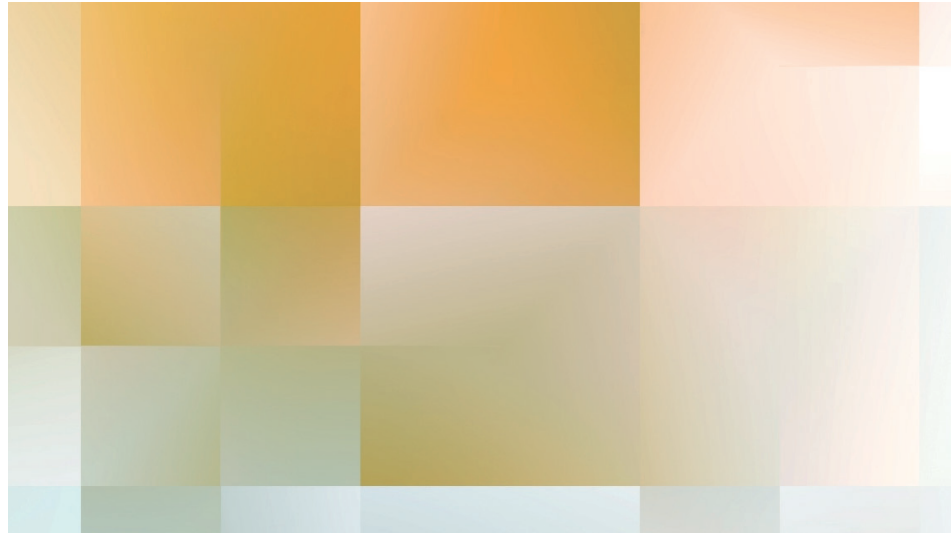

\section{METODOLOGIAS ATIVAS DE APRENDIZAGEM NA EDUCAÇÃO PROFISSIONAL E TECNOLÓGICA}

\author{
Eduardo Fernandes Barbosa* \\ Dácio Guimarães de Moura**
}

\section{Resumo}

A Educação Profissional tem sido objeto de discussões focalizando prioritariamente as organizações curriculares e percursos formativos, com menor ênfase em metodologias de aprendizagem voltadas para a construção de competências profissionais. Este artigo incentiva a revisão de práticas tradicionais de ensino e discute possibilidades de metodologias ativas na Educação Profissional, especialmente as metodologias Aprendizagem Baseada em Problemas e Aprendizagem Baseada em Projetos. Ambas têm um ideário favorável às necessidades da Educação Profissional e podem gerar práticas docentes inovadoras no contexto da formação profissional, superando limitações dos modelos tradicionais de ensino.

Palavras-chave: Metodologias ativas de aprendizagem. Aprendizagem Baseada em Problemas. Aprendizagem Baseada em Projetos. Educação Profissional e Tecnológica. 


\section{Abstract}

Active learning methods in Professional and Technological Education. Professional Education has been the subject of discussions focusing primarily the curriculum organizations and formative trajectories, with less emphasis on learning methodologies oriented to the construction of professional skills. This paper encourages the revision of traditional teaching practices and discusses possibilities of active methodologies in Professional Education, especially the Problem-based Learning and Project-based Learning methodologies. Both have favorable ideals to Professional Education needs and can generate innovative teaching practices in the contexts of vocational training, overcoming the traditional teaching models' limitations.

Keywords: Active Learning Methods. Problem-based Learning. Project-based Learning. Professional and Technological Education.

\section{Resumen}

Metodologías activas de aprendizaje en la Educación Profesional y Tecnológica. La Educación Profesional ha sido objeto de discusiones centrándose principalmente en las organizaciones curriculares y recorridos formativos, con menor énfasis en metodologías de aprendizaje orientadas a la construcción de habilidades profesionales. Este artículo estimula la revisión de prácticas tradicionales de enseñanza y discute posibilidades de metodologías activas en la Educación Profesional, especialmente las metodologías de Aprendizaje Basado en Problemas y Aprendizaje Basado en Proyectos. Ambas tienen un ideario favorable a las necesidades de la Educación Profesional y pueden generar prácticas de enseñanza innovadoras en el contexto de la formación profesional, superando las limitaciones de los modelos tradicionales de enseñanza.

Palabras clave: Metodologías activas de aprendizaje. Aprendizaje Basado en Problemas. Aprendizaje Basado en Proyectos. Educación Profesional y Tecnológica.

\section{Introdução}

\footnotetext{
A

tualmente, uma característica predominante nos diversos atores do contexto educacional é a expectativa crescente de mudanças, que pode ser resumida em duas palavras: ansiedade indefinida. Mesmo sem saber exatamente o que está por vir no cenário educacional, a expectativa generalizada é de que ocorram mudanças que façam alguma diferença na educação de nossos jovens.

Nas últimas décadas, o perfil do aluno mudou muito. A escola também mudou e sobrevive, hoje, em um contexto socioeconômico que impõe expectativas de desempenho cada vez mais elevadas. Espera-se que os egressos da Educação Profissional e Tecnológica (EPT) sejam capazes de transitar com desenvoltura e segurança em um mundo cada vez mais complexo e repleto de tecnologias inovadoras.
} 


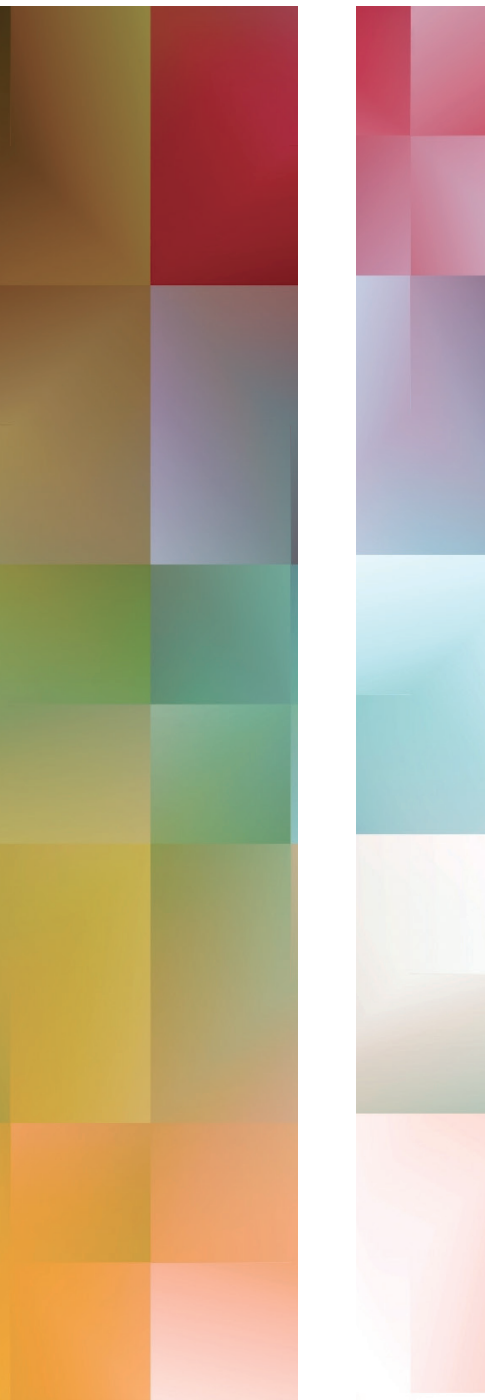

No Brasil, convivemos com contextos educacionais tão diversificados que vão desde escolas onde os alunos ocupam grande parte de seu tempo copiando textos passados no quadro até escolas que disponibilizam para alunos e professores os recursos mais modernos da informação e comunicação. Entre esses extremos de diversidade, encontramos escolas que estão no século XIX, com professores do século XX, formando alunos para o mundo do século XXI.

Como preparar profissionais para a próxima década se não temos ideia clara sobre como será a economia mundial nem a tecnologia dominante daqui a alguns meses? Que mudanças devem ocorrer no contexto escolar, na prática docente e no perfil do aluno para que a EPT atenda às necessidades contemporâneas do mundo do trabalho? Qual é a melhor organização e funcionamento da escola que atende à necessidade de ensinar conteúdos cada vez mais complexos e abrangentes? Quais seriam as práticas docentes mais adequadas para atender às demandas educacionais de nosso tempo? Não temos respostas para todas essas indagações. Mas o fato é que essas questões têm sido motivo de ensaios de previsão do futuro da educação, em todos os níveis e tipos de ensino, por especialistas do Brasil e do exterior.

Blikstein (2010) chama a atenção para:

[...] o grande potencial de aprendizagem que é desperdiçado em nossas escolas, diária e sistematicamente, em nome de ideias educacionais obsoletas. [...] É uma tragédia ver, a cada dia, milhares de alunos sendo convencidos de que são incapazes e pouco inteligentes simplesmente porque não conseguem se adaptar a um sistema equivocado (BLIKSTEIN, 2010, p. 3).

Miller, Shapiro, Hilding-Hamann (2008) apresentam visão do cenário educacional que deve ser uma realidade já nas primeiras décadas do século XXI. Nesse cenário, a escola tradicional seria transformada em espaços de aprendizagem, base de uma sociedade sustentada em aprendizagem intensiva. É uma visão de aprendizagem radicalmente diferente do modelo convencional de sala de aula, onde o quadro negro e o professor se impõem perante os alunos como a quinta-essência do espaço de aprendizagem da era industrial (MILLER; SHAPIRO; HILDING-HAMANN, 2008).

Caldwell e Spinks (1998) trazem considerações que devem direcionar o futuro da educação e da escola ao longo do século XXI, antevendo mudanças profundas na organização e funções da escola, muitas delas refletindo diretamente na sala de aula e em seus principais agentes - os alunos e os professores. Uma de suas previsões é que os fundamentos da educação vão-se expandir para incluir práticas de solução de problemas, estímulo à criatividade, inovação e capacitação do indivíduo para aprendizagem ao longo da vida (CALDWELL; SPINKS, 1998).

Araújo (2011) resume a situação atual na necessidade de reinventar a educação, tendo em vista que o modelo tradicional de escola, consolidado no século XIX, "tem agora, também, de dar conta das demandas e necessidades de uma sociedade democrática, inclusiva, permeada pelas diferenças e 
pautada no conhecimento inter, multi e transdisciplinar, com a que vivemos neste início de século 21" (ARAúJO, 2011, p. 39).

Em síntese, as projeções mais recentes para o futuro da educação indicam que a escola, como ela é hoje, tem poucas chances de sobrevivência nas próximas décadas. Neste trabalho, focalizamos nos processos que ocorrem na sala de aula e nas relações professor-aluno, partindo de reflexões sobre as metodologias que têm sido aplicadas nesse processo e em como as metodologias ativas podem contribuir para elevar a eficiência e eficácia da aprendizagem no contexto da educação profissional.

\section{Que tipo de aprendizagem precisamos na Educação Profissional?}

A resposta a essa pergunta depende do ponto em que nos encontramos no amplo espectro da diversidade educacional brasileira. Depende, também, da intensidade com que percebemos os impactos das Tecnologias da Informação e Comunicação (TIC), não só nos processos de aprendizagem, mas também na habilidade que o mundo do trabalho requer do futuro profissional no uso dessas tecnologias em seus processos produtivos.

Podemos dizer que a EPT requer uma aprendizagem significativa, contextualizada, orientada para o uso das TIC, que favoreça o uso intensivo dos recursos da inteligência, e que gere habilidades em resolver problemas e conduzir projetos nos diversos segmentos do setor produtivo. Como contraponto, podemos dizer que a aprendizagem em EPT deve estar cada vez mais distante da aprendizagem tradicional, fundamentada no poder do verbo, teórica e dependente do uso intensivo da memória.

Complementando esses requisitos de aprendizagem, devemos acrescentar que, mesmo que o sistema educacional forme indivíduos tecnicamente muito bem preparados, é indispensável que eles sejam capazes de exercer valores e condições de formação humana, considerados essenciais no mundo do trabalho contemporâneo, tais como: conduta ética, capacidade de iniciativa, criatividade, flexibilidade, autocontrole, comunicação, dentre outros.

Do ponto de vista de habilidades básicas, é preocupante notar que algumas estão pouco desenvolvidas no processo de aprendizagem em EPT. Nos cursos da área tecnológica, por exemplo, Goldberg (2010) aponta sete habilidades básicas que estão faltando na formação de nossos jovens. Nessa área, nossos alunos estão tendo dificuldades em: (1) fazer boas perguntas; (2) nomear objetos tecnológicos; (3) modelar processos e sistemas qualitativamente; (4) decompor problemas complexos em problemas menores; (5) coletar dados para análise; (6) visualizar soluções e gerar novas ideias; e (7) comunicar soluções de forma oral e por escrito (GOLDBERG, 2010).

Cada uma dessas habilidades, consideradas como lacunas na aprendizagem de nossos alunos, na área tecnológica, poderia ser objeto de uma discussão 
detalhada e profunda sobre causas, consequências e formas de preencher esse vazio. A questão que surge a partir dessa lista de habilidades faltantes na formação em EPT é: qual é a estratégia metodológica mais adequada para preencher essa necessidade de formação profissional?

\section{Novas tecnologias e seus impactos na aprendizagem}

Outra questão corrente que interessa ao sistema de EPT é a inclusão das TICs no processo formativo do futuro profissional. Não há dúvida quanto à sua necessidade no contexto educacional, por se tratar de um conhecimento imprescindível em qualquer área da atividade humana. Entretanto, ainda há dúvidas quanto à melhor forma de promover essa inclusão no processo educativo e avaliar sua efetiva contribuição para a aprendizagem. Implantar infraestrutura tecnológica nas escolas é apenas parte da inclusão das TICs na educação.

Conforme Barbosa (2012), pesquisas sobre inclusão das TIC na educação mostram que:

Existem outras dimensões da apropriação das TIC nos processos educacionais que também precisam ser medidas e avaliadas: as habilidades no uso da tecnologia, os principais elementos motivadores e as principais limitações que impedem o seu uso pelos atores do sistema educacional. [...] Para as escolas e educadores, aplicar as novas tecnologias nos processos de ensino-aprendizagem ainda é um desafio. O futuro da própria pedagogia e dos métodos de ensino como os conhecemos a partir da adoção das TIC ainda é uma questão sem resposta clara (BARBOSA, 2012, p. 21).

A questão do uso das TICs como recurso para tornar mais eficiente e efetiva a aprendizagem parece ser uma das causas da ansiedade indefinida dos educadores, à qual nos referimos anteriormente. A cada nova geração de artefatos tecnológicos, aumentam as dúvidas sobre como será a educação nas próximas décadas. Os indicadores de inclusão tecnológica mostram claramente que o acesso às novas tecnologias vem aumentando ano a ano. Mas e os impactos na aprendizagem? Nossos alunos estão aprendendo mais e melhor com o uso das TICs? (LIMA, 2012).

\section{Onde as mudanças são mais esperadas e necessárias}

No Brasil, não temos ainda avaliação sistêmica da EPT. Tomemos, então, como referência para nossa reflexão o baixo desempenho do ensino médio nos últimos anos. Uma causa apontada é o excesso de conteúdos nesse nível de ensino. De fato, nossos alunos têm dificuldade em administrar o excesso conteudista. Entretanto, 
atribuir apenas ao conteúdo a causa do problema de baixo desempenho pode levar a uma solução fácil, mas pouco eficaz: editar mais uma diretriz para reorganizar ou limitar os conteúdos.

Na prática, um decreto não resolve o problema de metodologias obsoletas ou inadequadas para os novos conteúdos. Um decreto a mais também não capacita professores em novos métodos de ensino nem dá às escolas a condição de organizar tempos e espaços necessários para inovações metodológicas em EPT. Ou seja, reorganizar currículos, sem a devida capacitação de professores, pode não gerar os resultados desejados. É nesse cenário que as metodologias ativas se apresentam como contribuição relevante na criação de ambientes de aprendizagem contextualizada, com impactos de grande interesse para a formação em EPT.

Em uma indústria, a expressão chão de fábrica é usada para designar o espaço onde o processo produtivo efetivamente acontece. Por analogia, podemos dizer que o chão de fábrica de uma escola é a sala de aula. É ali onde as relações entre professor e aluno realizam as funções complementares de ensinar e aprender. É também nesse ambiente onde encontramos as limitações que mais afetam a eficiência do sistema educacional em todos os níveis e tipos de ensino. A nosso ver, o aprimoramento das funções básicas de ensinar e aprender, por meio de metodologias ativas, é um complemento necessário às propostas de reorganização curricular em curso.

\section{O que são metodologias ativas de aprendizagem?}

A expressão Metodologias Ativas de Aprendizagem pode parecer novidade para o professor que atua no campo da EPT. Mas, pelo menos em suas formas mais simples, os professores conhecem meios de ensinar e aprender que podem ser considerados como um tipo de metodologia ativa, ainda que não sejam rotuladas ou conhecidas por essa expressão. $\mathrm{O}$ ensino por meio de projetos, assim como o ensino por meio da solução de problemas, são exemplos típicos de metodologias ativas de aprendizagem.

Para introduzir o conceito que queremos delinear, é oportuno lembrar um provérbio chinês que diz: "O que eu ouço, eu esqueço; o que eu vejo, eu lembro; o que eu faço, eu compreendo." Isso foi dito pelo filósofo Confúcio e tem relação direta com aprendizagem ativa. Silberman (1996) modificou esse provérbio para facilitar o entendimento de métodos ativos de aprendizagem, dando a ele a seguinte redação:

- O que eu ouço, eu esqueço;

- O que eu ouço e vejo, eu me lembro;

- O que eu ouço, vejo e pergunto ou discuto, eu começo a compreender;

- O que eu ouço, vejo, discuto e faço, eu aprendo desenvolvendo conhecimento e habilidade;

- O que eu ensino para alguém, eu domino com maestria. 
Essa citação, com a modificação de Silberman (1996), resume os princípios das metodologias ativas de aprendizagem. Se nossa prática de ensino favorecer no aluno as atividades de ouvir, ver, perguntar, discutir, fazer e ensinar, estamos no caminho da aprendizagem ativa.

\section{Sobre o conceito de aprendizagem ativa}

Geralmente, a expressão aprendizagem ativa, que pode ser entendida também como aprendizagem significativa, é usada de forma vaga e imprecisa. Intuitivamente, professores imaginam que toda aprendizagem é inerentemente ativa. Muitos consideram que o aluno está sempre ativamente envolvido enquanto assiste a uma aula expositiva. Entretanto, pesquisas da ciência cognitiva sugerem que os alunos devem fazer algo mais do que simplesmente ouvir, para ter uma aprendizagem efetiva (MEYERS; JONES, 1993).

Para se envolver ativamente no processo de aprendizagem, o aluno deve ler, escrever, perguntar, discutir ou estar ocupado em resolver problemas e desenvolver projetos. Além disso, o aluno deve realizar tarefas mentais de alto nível, como análise, síntese e avaliação. Nesse sentido, as estratégias que promovem aprendizagem ativa podem ser definidas como sendo atividades que ocupam o aluno em fazer alguma coisa e, ao mesmo tempo, o leva a pensar sobre as coisas que está fazendo (BONWELL; EISON, 1991; SILBERMAN, 1996).

Assim, aprendizagem ativa ocorre quando o aluno interage com o assunto em estudo - ouvindo, falando, perguntando, discutindo, fazendo e ensinando sendo estimulado a construir o conhecimento ao invés de recebê-lo de forma passiva do professor. Em um ambiente de aprendizagem ativa, o professor atua como orientador, supervisor, facilitador do processo de aprendizagem, e não apenas como fonte única de informação e conhecimento.

Independentemente do método ou da estratégia usada para promover a aprendizagem ativa, é essencial que o aluno faça uso de suas funções mentais de pensar, raciocinar, observar, refletir, entender, combinar, dentre outras que, em conjunto, formam a inteligência, segundo a concepção de Pecotche (2011). Em outras palavras, a diferença fundamental que caracteriza um ambiente de aprendizagem ativa é a atitude ativa da inteligência, em contraposição à atitude passiva geralmente associada aos métodos tradicionais de ensino.

Ressaltamos ainda que, tão importante quanto pensar no que está fazendo, é sentir o que está fazendo. A participação dos sentimentos deve ser vista como um fator relevante na fixação do conhecimento. Podemos dizer que o bom humor, a boa disposição e a alegria são os lubrificantes das engrenagens do entendimento e da aprendizagem (SHAH; NIHALANI, 2012). 
É importante notar que aprendizagem ativa se refere a estratégias para ativar o aluno. O professor, em princípio, está (ou deveria estar) em uma posição ativa ao ensinar, pois tem de recorrer a seus estudos, selecionar informação, escolher terminologia adequada, explicar um conhecimento de diferentes formas, fazer relações, comparações, analogias etc. Subtende-se que, se o professor aplica o mesmo plano de aula dezenas de vezes, sem inovações, é provável que, neste caso, sua exposição se torne rotineira, automática e, logicamente, terá um caráter passivo e não ativo.
Com métodos ativos, os alunos assimilam maior volume de conteúdo, retêm a informação por mais tempo e aproveitam as aulas com mais satisfação e prazer

\section{O que podemos esperar da aprendizagem ativa?}

Pesquisas mostram que a aprendizagem ativa é uma estratégia de ensino muito eficaz, independentemente do assunto, quando comparada com os métodos de ensino tradicionais, como aula expositiva. Com métodos ativos, os alunos assimilam maior volume de conteúdo, retêm a informação por mais tempo e aproveitam as aulas com mais satisfação e prazer (SILBERMAN, 1996).

A experiência indica que a aprendizagem é mais significativa com as metodologias ativas de aprendizagem. Além disso, os alunos que vivenciam esse método adquirem mais confiança em suas decisões e na aplicação do conhecimento em situações práticas; melhoram o relacionamento com os colegas, aprendem a se expressar melhor oralmente e por escrito, adquirem gosto para resolver problemas e vivenciam situações que requerem tomar decisões por conta própria, reforçando a autonomia no pensar e no atuar (RIBEIRO, 2005).

\section{Adequabilidade de métodos ativos para a EPT}

A educação profissional oferece muitas oportunidades de aplicar metodologias ativas de aprendizagem nas diferentes áreas de formação profissional. É o caso das aulas de laboratório, oficinas, tarefas em grupo, trabalhos em equipe dentro e fora do ambiente escolar, visitas técnicas e desenvolvimento de projetos. Essas atividades tendem a ser naturalmente participativas e promovem o envolvimento do aluno no processo de aprendizagem.

Entretanto, se de um lado vivenciamos com mais facilidade os métodos ativos de aprendizagem nas atividades práticas, por outro lado, resta-nos enfrentar um dos grandes desafios pedagógicos dos tempos modernos: incorporar aprendizagem ativa nos espaços e tempos atualmente ocupados pelas tradicionais aulas expositivas. É exatamente ali, na sala de aula e nas relações entre professor e aluno, onde as mudanças são mais necessárias. 


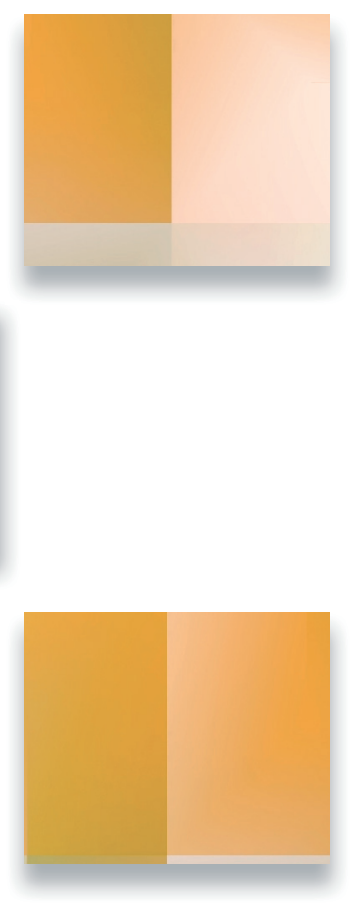

Dentre as diversas estratégias que podem ser usadas para se conseguir ambientes de aprendizagem ativa em sala de aula, destacamos as seguintes (BONWELL; EISON, 1991):

- Discussão de temas e tópicos de interesse para a formação profissional.

- Trabalho em equipe com tarefas que exigem colaboração de todos.

- Estudo de casos relacionados com áreas de formação profissional específica.

- Debates sobre temas da atualidade.

- Geração de ideias (brainstorming) para buscar a solução de um problema.

- Produção de mapas conceituais para esclarecer e aprofundar conceitos e ideias.

- Modelagem e simulação de processos e sistemas típicos da área de formação.

- Criação de sites ou redes sociais visando aprendizagem cooperativa.

- Elaboração de questões de pesquisa na área científica e tecnológica.

Em princípio, todo método ou estratégia que promova o envolvimento e a participação ativa do aluno no processo de desenvolvimento do conhecimento contribui para formar ambientes ativos de aprendizagem. Nas próximas seções, abordamos duas metodologias sistematizadas para promover a aprendizagem ativa: a Aprendizagem Baseada em Problemas (ABP) e Aprendizagem Baseada em Projetos (ABP). Também em inglês usa-se a mesma sigla - PBL, para designar as duas metodologias: Problem Based Learning e Project Based Learning. Para evitar confusão, adotamos a expressão ABProb e ABProj para aprendizagem baseada em prob/emas e em projetos, respectivamente.

\section{Aprendizagem Baseada em Problemas (ABProb)}

A ideia de trabalhar com problemas como meio para ensinar e aprender é bem antiga. É conhecida a história do filósofo Confúcio (500 a.C.), que só ajudava a seus seguidores na resposta a algum problema ou questão depois que eles tivessem feito algum esforço próprio na busca da solução.

A sistematização da metodologia de Aprendizagem Baseada em Problemas - ABProb, como é conhecida hoje, surgiu na década de 1960 no Canadá, onde foi aplicada inicialmente em escolas de Medicina. Apesar da aplicação inicial na área médica, a ABProb tem sido utilizada em várias outras áreas do conhecimento, como: administração, arquitetura, ciências da computação, ciências sociais, economia, engenharias e matemática (ARAúJO, 2011).

No Brasil, há interesse crescente por essa metodologia e algumas escolas aplicam a ABProb regularmente em seus cursos. É o caso da Escola de Artes, Ciências e Humanidades da Universidade de São Paulo - EACH/USP, onde a ABProb foi incluída no currículo de dez cursos de graduação como método-base das disciplinas Resolução de Problemas desde 2005 (ARAÚJO, 2011). 
Esse método de ensino fundamenta-se no uso contextualizado de uma situação problema para o aprendizado autodirigido. Enquanto que nos métodos convencionais o objetivo é a transmissão do conhecimento centrada no professor, em conteúdos disciplinares, na ABProb, o aprendizado passa a ser centrado no aluno, que deixa de ser um receptor passivo da informação para ser agente ativo por seu aprendizado. Nesse contexto, o professor atua como orientador ou facilitador nos grupos de trabalho ou estudo, nos quais a interação entre professor-aluno é muito mais intensa do que em aulas puramente expositivas.

A ABProb admite sequencias de trabalho que podem variar conforme o nível e tipo de ensino, com a área do conhecimento e com os objetivos de aprendizagem que se quer alcançar. Em linhas gerais, ABProb inclui as etapas mostradas na Figura 1.

1

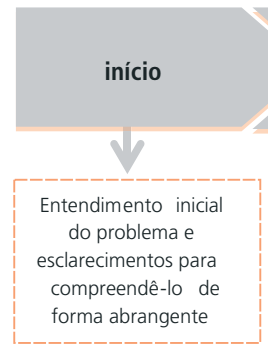

5
2

3

Elaboração

de Questões

\begin{tabular}{|c|c|c|c|}
\hline \multicolumn{1}{c}{$\mathbf{5}$} & $\mathbf{6}$ & $\mathbf{7}$ & $\mathbf{8}$ \\
$\begin{array}{c}\text { Objetivos de } \\
\text { Apren dizagem }\end{array}$ & Estudo & $\begin{array}{c}\text { Síntese } \\
\text { e Avaliação }\end{array}$ & Apresentação \\
\hline $\begin{array}{c}\text { Op que se espera } \\
\text { aprender com os } \\
\text { resultados do } \\
\text { trabalho? }\end{array}$ & $\begin{array}{c}\text { Estudo i ndividual e } \\
\text { discussão em grupo, } \\
\text { com registro do } \\
\text { processo seguido }\end{array}$ & $\begin{array}{c}\text { Síntese/avaliação do } \\
\text { trabalho } \\
\text { desenvolvido e } \\
\text { resultados obtidos }\end{array}$ & $\begin{array}{c}\text { Mostra do trabalho } \\
\text { desenvolvido para o } \\
\text { grupo: resultados, } \\
\text { processos, análise }\end{array}$ \\
\hline
\end{tabular}

Figura 1 - Etapas de aplicação da ABProb

Fonte:ARAÚJO (2011)

Observe que em cada etapa de aplicação da ABProb o aluno tem a oportunidade de envolvimento com tarefas que favorecem a assimilação e fixação do conhecimento, partindo do entendimento inicial do problema proposto, passando pelas fases de análise e busca de uma solução até a apresentação do trabalho e análises dos resultados.

A ABProb procura transformar um problema como base de motivação para o aprendizado autodirigido, dando ênfase à construção do conhecimento em ambiente de colaboração mútua. A ideia não é ter sempre o problema resolvido na etapa final 
do trabalho, mas sim enfatizar o processo seguido pelo grupo na busca de uma solução, valorizando a aprendizagem autônoma e cooperativa.

Como podemos ver, a ABProb difere muito dos métodos convencionais de aprendizagem. Portanto, é de se esperar que tanto os professores como os alunos assumam funções diferentes das que estão acostumados no ensino convencional. O Quadro 1 ilustra algumas dessas diferenças.

Quadro 1-Requisitos para professor e aluno no ensino convencional e na ABProb

Ensino convencional

Abordagem da ABProb

\begin{tabular}{ll|l}
\hline & Função de especialista ou autoridade formal & Orientador, coaprendiz ou consultor \\
\cline { 2 - 3 } & Trabalho isolado & Trabalho em equipe \\
\hline Transmissor de informação aos alunos & Ensina ao aluno gerenciar sua aprendizagem \\
\hline Conteúdo organizado em aula expositiva & Curso organizado em problemas reais \\
\hline Trabalho individual por disciplina & Estímulo ao trabalho interdisciplinar \\
\hline
\end{tabular}

\begin{tabular}{|c|c|c|}
\hline \multirow{8}{*}{$\frac{O}{\frac{丶}{3}}$} & Receptores passivos da informação & Valorização do conhecimento prévio \\
\hline & Trabalho individual isolado & Interação com colegas e professores \\
\hline & Transcrevem, memorizam e repetem & Função de buscar/construir o conhecimento \\
\hline & Aprendizagem individualista e competitiva & Aprendizagem em ambiente colaborativo \\
\hline & Busca resposta certa para sair bem na prova & Busca questionar e equacionar problemas \\
\hline & Avaliação dentro de conteúdos limitados & Análise e solução ampla de problemas \\
\hline & Avaliação somativa e só o professor avalia & Aluno e o grupo avaliam contribuições \\
\hline & Aula baseada em transmissão da informação & $\begin{array}{l}\text { Trabalho em grupo para buscar soluções; } \\
\text { conhecimento é aplicado em vários } \\
\text { contextos; busca da informação com } \\
\text { orientação docente }\end{array}$ \\
\hline
\end{tabular}

Quando dizemos que a ABProb é um método educacional centrado no aluno, devemos entender que as oportunidades de aprendizagem devem ser relevantes para eles. Nesse contexto, a responsabilidade pela aprendizagem deve ser atribuída a eles de forma explícita, sem que isso signifique diminuir em nada a responsabilidade do professor. Equivale a dizer que a responsabilidade de aprender é, em última instância, do aluno.

Nem mesmo um professor excepcional poderá promover a aprendizagem de maneira forçada ou compulsória. O que se quer dizer com atribuir explicitamente a responsabilidade de aprendizagem ao aluno é que ele deve ser consciente de sua parcela de responsabilidade no processo de aquisição do conhecimento. Se ele não quiser e não fizer sua parte, o processo não chega 
a bom termo, por mais que o professor se empenhe nisso, independente do método empregado para ensinar.

\section{Requisitos da ABProb para o professor}

A maior necessidade que a ABProb apresenta para os professores é o fato de que a maioria deles não teve experiência nesse método em seu processo de formação docente. Na aplicação da ABProb o professor tem funções mais amplas e complexas do que nos métodos convencionais de ensino. Nesse sentido, o professor deve: mediar discussões; atuar para manter grupos de alunos focados em um problema ou questão específica; motivar alunos a se envolverem com as tarefas requeridas no processo de busca de solução; estimular o uso da função de pensar, observar, raciocinar e entender.

Tudo isso vai muito além - e é mais complexo - do que o professor se apresentar perante os alunos e dar uma aula expositiva, da mesma forma em que vem fazendo por anos a fio. Isso significa que o professor deve, antes de ativar a inteligência do aluno, ativar a própria inteligência, de tal maneira que seu exemplo sirva de inspiração para o aluno. Como exemplo, podemos dizer que para ensinar ao aluno a pensar é necessário que o professor tenha experimentado o que significa um esforço mental neste sentido e não apenas uma definição teórica do que é o exercício da função de pensar.

\section{Requisitos da ABProb para a instituição escolar}

É lógico prever que uma abordagem centrada no aluno e não no professor, venha demandar adequações de espaço e tempos escolares diferenciados em relação às práticas tradicionais de ensino. Não só deverá haver investimento na formação e capacitação dos professores, mas também do próprio corpo técnico e administrativo e, em muitos casos, na infraestrutura da escola. A ABProb pode requerer adequação de mobiliário e equipamentos próprios que permitam trabalhos e discussões em grupos informais e mobilização de espaços fora da sala de aula. O aluno deve se sentir motivado a buscar material de apoio, seja no interior da instituição (laboratórios, biblioteca, salas ambiente, etc.), seja no ambiente externo à mesma. Há estudos mostrando que até a disposição do mobiliário nas salas de aula pode influir no desempenho do aluno na aplicação das metodologias ativas (RIBEIRO, 2005).

\section{Aprendizagem Baseada em Projetos (ABProj)}

Projetos são empreendimentos finitos com objetivos bem definidos e nascem a partir de um problema, uma necessidade, uma oportunidade ou interesses de uma pessoa, um grupo de pessoas ou uma organização. Quanto à tipologia, os projetos podem ser do tipo intervenção, desenvolvimento, pesquisa, ensino e aprendizagem. Embora todo projeto seja uma atividade instrutiva por excelência, no escopo deste trabalho, consideramos apenas os projetos 
de aprendizagem como recurso pedagógico para aprendizagem significativa e contextualizada, no âmbito da EPT (MOURA; BARBOSA, 2011).

A ideia de trabalhar com projetos como recurso pedagógico na construção de conhecimentos remonta ao final do século XIX, a partir de ideias enunciadas por John Dewey, em 1897. Entretanto, o trabalho com a Metodologia de Projetos (MP) remonta ao final do século XVII na Itália, sob uma perspectiva de ensino profissionalizante, especificamente na área da Arquitetura (KNOLL, 1997).

John Dewey e William H. Kilpatrick, ambos do início do século XX, são considerados os precursores da Aprendizagem Baseada em Projetos na era contemporânea. Na visão de Kilpatrick, o projeto com fins educacionais teria quatro fases essenciais: intenção, planejamento, execução, e julgamento. Dewey considerava que os projetos realizados por alunos demandam necessariamente a ajuda de um professor que pudesse assegurar o processo contínuo de aprendizagem e crescimento.

Diversas publicações e experiências escolares referem-se ao potencial dos projetos de aprendizagem (também chamados de projetos de trabalho) como contribuição de alto valor para o processo educativo, como Moura (1993); Higino (2002); Freitas (2003); Barbosa, Gontijo e Santos (2004); Pires (2006); Godoy (2009); Mayra Araujo (2009); Ulisses Araujo (2009) e Costa (2010), especialmente no que diz respeito à promoção de uma aprendizagem significativa, em contraposição à aprendizagem tradicional do tipo verbal, retórica, livresca, de ênfase teórica e descontextualizada. Essas características da ABProj são de grande valor nos processos formativos da EPT.

\section{Alguns pressupostos da Aprendizagem Baseada em Projetos}

Um dos pressupostos da ABProj é a consideração de situações reais relativas ao contexto e à vida, no sentido mais amplo, que devem estar relacionadas ao objeto central do projeto em desenvolvimento.

A adoção desse pressuposto significa uma contribuição para a superação do modelo tradicional de educação centrada na abstração, no poder do verbo. A propósito, é oportuno enfatizar que essa hegemonia da educação verbal pode tornar-se ainda mais poderosa como consequência indireta das formas atuais de valorização do fator informação, que tende a tornar-se cada vez mais atraente e disponível através das novas tecnologias da informação, reforçando, progressivamente, a dimensão "virtual" nos ambientes educacionais.

Assim, a adoção da ABProj pode ser uma forma importante de compensar problemas decorrentes do uso exagerado de recursos virtuais, em detrimento de situações reais e contextuais. Essa é uma questão que se apresenta atualmente em relação à utilização de softwares educativos idealizados para simulação de situações da vida real. Consideramos de grande importância o aprofundamento dessa questão em estudos à parte, tal como realizado por Godoy (2009). 


\section{A era da informação e aprendizagem significativa}

A tendência atual de valorização da chamada dimensão virtual, associada fortemente ao fator informação, pode, em termos do desenvolvimento educacional dos jovens estudantes, induzir dificuldades e problemas complexos relacionados às necessidades de formação do indivíduo. A formação do ser humano, em caráter integral, demanda o desenvolvimento de um equilíbrio fundamental entre fatores relativos à abstração racional e fatores relativos ao desenvolvimento sensível e sensório-motor. A proposta de aprendizagem por meio de projetos representa uma forma importante de considerar todos os elementos referentes à formação integral do ser humano (MOURA, 1993).

Muitos conceitos e habilidades intelectivas construídas com métodos tradicionais de ensino acabam tendo pouco ou nenhum significado para os alunos, resultando em uma formação deficiente no contexto da EPT. Uma referência sobre a aprendizagem significativa e que faz um paralelo com a ABProj é dada por Gadotti (1994):

A aprendizagem significativa verifica-se quando o estudante percebe que o material a estudar se relaciona com os seus próprios objetivos. [...] É por meio de atos que se adquire aprendizagem mais significativa. A aprendizagem é facilitada quando o aluno participa responsavelmente do seu processo. A aprendizagem autoiniciada que envolve toda a pessoa do aprendiz - seus sentimentos tanto quanto sua inteligência - é a mais durável e penetrante (GADOTTI, 1994).

Segundo Hernandéz e Ventura (1998), a ABProj propõe a formação de indivíduos com uma visão global da realidade, vinculando a aprendizagem a situações e problemas reais, preparando para a aprendizagem ao longo da vida. A relação entre a Metodologia de Projetos e a aprendizagem significativa é resumida por Aguiar (1995):

As situações que nos parecem mais favoráveis ao processo de construção são aquelas em que o aluno participa efetivamente do planejamento das atividades, com objetivos claramente estabelecidos, mesmo que as tarefas e seu significado venham a se modificar ao longo da execução do projeto negociado com a turma. Quanto maior o envolvimento do aprendiz com o seu processo de aprendizagem, com os objetivos de seu conhecimento, maiores serão as possibilidades de uma aprendizagem significativa, de uma mudança conceitual efetiva e duradoura. Além disso, o processo favorece não apenas a aprendizagem de conceitos, mas ainda de procedimentos e atitudes em relação ao conhecimento e ao trabalho cooperativo (AGUIAR, 1995).

\section{Algumas diretrizes para os projetos de aprendizagem em ABProj}

Os projetos desenvolvidos pelos alunos no contexto escolar podem apresentar variações. Moura (1993) apresenta uma classificação de projetos de 
trabalho, também denominados Projetos de Aprendizagem, que tem sido utilizada em diversas situações na Educação Profissional, com resultados positivos conforme analisados por Wanderley (1999) e Higino (2002). Os projetos desenvolvidos sob a metodologia de ABProj podem ser classificados em três categorias:

- Projeto construtivo: tem em vista construir algo novo, introduzindo alguma inovação, propor uma solução nova para um problema ou situação. Possui a dimensão da inventividade, seja na função, na forma ou no processo.

- Projeto investigativo: destina-se ao desenvolvimento de pesquisa sobre uma questão ou situação, mediante o emprego do método científico.

- Projeto didático (ou explicativo): procura responder questões do tipo: "Como funciona? Para que serve? Como foi construído?" Busca explicar, ilustrar, revelar os princípios científicos de funcionamento de objetos, mecanismos, sistemas etc.

Podemos resumir do seguinte modo algumas diretrizes que consideramos fundamentais para o desenvolvimento de Projetos de Trabalho (MOURA; BARBOSA, 2011):

- Realização de projetos por grupos de alunos com o número de participantes definido criteriosamente para cada experiência (Ex.: 4 alunos por grupo).

- Definição de um período de tempo para a realização do projeto, como fator importante no seu desenvolvimento e concretização (Ex.: 2 a 4 meses).

- A escolha do tema mediante negociação entre alunos e professores, considerando múltiplos interesses e objetivos didático-pedagógicos.

- Os projetos devem contemplar uma finalidade útil de modo que os alunos tenham uma percepção de um sentido real dos projetos propostos.

- Uso de múltiplos recursos no desenvolvimento dos projetos incluindo aqueles que os próprios alunos podem providenciar junto a fontes diversas, dentro ou fora do ambiente escolar.

- Socialização dos resultados dos projetos em diversos níveis de comunicação, como a própria sala de aula, a escola e a comunidade.

\section{A experiência dos autores}

Os autores deste trabalho vivenciaram inúmeras experiências com as metodologias ABProb e ABProj, tanto na aplicação direta dessas metodologias com seus alunos de EPT, como em projetos de pesquisa em cursos de pós-graduação em Educação Tecnológica. Ao longo de vários anos, temos comprovado os benefícios dessas metodologias para a formação profissional no âmbito da EPT. A conclusão mais importante é que ambos os métodos são de grande eficácia na construção do conhecimento contextualizado e aquisição de habilidades para a formação de um profissional em sintonia com necessidades do mundo do trabalho contemporâneo (BARBOSA; GONTIJO; SANTOS, 2004; MOURA; BARBOSA, 2011). 


\section{Comparação de Métodos - ABProb versus ABProj}

Embora o ideário e as orientações pedagógicas das duas metodologias, ABProb e ABProj, sejam comuns e favoráveis à realização dos objetivos da EPT, existem diferenças significativas entre elas. O Quadro 2 mostra uma comparação entre as duas metodologias.

Quadro 2-Comparação dos métodos ABProb versusABProj

\begin{tabular}{|c|c|}
\hline \multicolumn{2}{|l|}{ ABProb } \\
\hline Tem origem em Problemas & $\begin{array}{l}\text { Situação-geradora (Problemas, necessidades, } \\
\text { oportunidade, interesse, etc.) }\end{array}$ \\
\hline Problema: mais contextual do que teórico & Situação geradora: contextual ou teórica \\
\hline $\begin{array}{l}\text { Problemas definidos pelo professor (garante } \\
\text { cobertura de conteúdos de interesse do Curso/ } \\
\text { professor) }\end{array}$ & $\begin{array}{l}\text { Situação geradora/problemas definidos pelos } \\
\text { alunos mediados pelo professor (maior potencial } \\
\text { de motivação dos alunos) }\end{array}$ \\
\hline Curta duração (2 a 4 semanas) & Média duração (4 a 12 semanas) \\
\hline Percurso com etapas bem definidas & Percurso com etapas mais abertas e flexíveis \\
\hline Proposta de análise/solução de um problema & Proposta de desenvolver algo novo \\
\hline Produto final não obrigatório & Requer um produto final \\
\hline \multicolumn{2}{|c|}{ Formação efetiva para o mundo do trabalho } \\
\hline \multicolumn{2}{|c|}{ Favorece aprendizagem contextualizada e significativa } \\
\hline \multicolumn{2}{|c|}{ Requer disposição e habilidades específicas do professor e do aluno } \\
\hline \multicolumn{2}{|c|}{ Método de ensino centrado no aluno } \\
\hline \multicolumn{2}{|c|}{ Favorece a interdisciplinaridade } \\
\hline nvolvime & da criatividade e inovação \\
\hline
\end{tabular}

\section{Considerações finais}

Tanto a ABProj como a ABProb possuem ideário claramente favorável à realização dos objetivos da Educação Profissional de nível técnico e tecnológico, o que faz delas um foco de interesse, especialmente quanto à sua aplicação em práticas inovadoras na formação profissional.

Aprendizagem significativa e contextualizada, construção de conhecimentos, habilidades e competências, trabalho cooperativo, solução de problemas, realização de projetos que transformam ideias em resultados, etc. são alguns dos benefícios comprovados de ambas as metodologias. Na sua essência, as duas metodologias são recursos pedagógicos para o aprender fazendo. Entretanto, não se trata apenas de fazer coisas, independente de critérios, 
escolhas, planos, objetivos de aprendizagem, orientação e acompanhamento criterioso. É necessário pensar no que se vai fazer, fazer o que se pensou e pensar no que se fez. O que se busca é a prática de uma atitude consciente diante da realidade que se quer modificar e dos conhecimentos e habilidades que se quer adquirir.

É possível ensinar qualquer área do conhecimento por meio de projetos? Essa é uma pergunta comum quando os professores tomam contato com a ABP's. Nossa resposta é "depende". De modo geral, podemos dizer que nem tudo pode ser ensinado via ABProb ou ABProj. Consideramos que, na maioria das áreas de conhecimento, deve haver um mínimo de conceituação inicial como base para criar, pensar, fazer, aprender. Portanto, ABP's não são uma panaceia educacional que veio para resolver os problemas da EPT ou de qualquer nível ou tipo de ensino. Sempre será necessário um mínimo de aulas expositivas, seja para apresentar conceitos básicos, seja para uma visão geral de um conhecimento que depois será aprendido em detalhes - e com o necessário aprofundamento - via $\mathrm{ABP}^{\prime}$ s.

Um contraponto para as ABP's é considerar que existem ótimos profissionais que se formaram pela via dos métodos tradicionais de ensino. Esse aspecto sugere que não se trata de usar sem critérios uma ou outra metodologia só pelo fato de ser inovadora ou porque promete resultados que ultrapassam os limites dos métodos tradicionais de ensino. Aulas expositivas (como as famosas lectures utilizadas em outros países) têm também sua função específica que é preciso identificar e explorar.

É importante reafirmar que os alunos de EPT que foram expostos ao ABProb ou ABProj vivenciam experiências de aprendizagem muito positivas e o conhecimento adquirido por essa via é de um valor inquestionável em seu processo formativo.

Finalmente, cabe lembrar que a ABProj geralmente é questionada pelo risco intrínseco que esse método apresenta de não se cobrir todo o conteúdo previsto para uma disciplina ou curso. Na ABProb esse risco é menor, pois os temas sobre os quais se apresentam os problemas são escolhidos pelo professor. Ou seja, há um mínimo de controle do conteúdo que se pretende ensinar. Entretanto, um método educacional inovador como as $\mathrm{ABP}^{\prime} \mathrm{s}$ traz tantas vantagens que as perdas, se existirem, se tornam insignificantes. Além disso, é possível conjugar as duas metodologias ABP's para favorecer e fazer bom uso do que cada uma delas propicia.

As contribuições das metodologias ativas nos permitem prever que, em vez de alunos saindo da escola com a ilusão de terem aprendido algo só porque foram expostos a conteúdos em aulas expositivas, teremos alunos que experimentaram situações de aprendizagem profundamente significativas em suas vidas. Se sentirem falta de algum tópico, saberão onde encontrá-lo e o que fazer para aprendê-lo. Só assim podemos criar uma geração de alunos com verdadeiro prazer na busca do conhecimento, com a noção clara de que a função de aprender não termina quando saem da escola e que estarão sempre prontos para enfrentar novos problemas e conduzir projetos inovadores (BLIKSTEIN, 2010). 
Nossa conclusão é que ambas as metodologias ativas apresentadas, ABProb e ABProj, têm muito a oferecer para melhorar a eficiência e eficácia da aprendizagem no contexto da Educação Profissional e Tecnológica no Brasil.

\section{Referências}

AGUIAR, J. O. G. Mudança conceitual em sala de aula: o ensino de ciências numa perspectiva construtivista. 1995. Dissertação (Mestrado em Educação Tecnológica) - Cefet-MG, Belo Horizonte, 1995.

ALENCAR, M. N. Origem da metodologia de projetos, seu significado, trajetória e contribuiç̧̃̃es nos processos educativos. Dissertação (Mestrado em Educação Tecnológica) Cefet-MG, Belo Horizonte, 2011.

ARAÚJO, Mayra C. M. Competências do professor para o trabalho com a metodologia de projetos de forma eficaz. Dissertação (Mestrado em Educação Tecnológica) - Cefet-MG, Belo Horizonte, 2009.

ARAÚJO, Ulisses F. Aprendizagem baseada em problemas no ensino superior. São Paulo: Summus, 2009.

ARAÚJO, Ulisses F. A quarta revolução educacional: a mudança de tempos, espaços e relações na escola a partir do uso de tecnologias e da inclusão social. ETD: educação temática digital, Campinas, v. 12, 2011. Número especial. Disponível em: <http://www.fae.unicamp.br/revista/index.php/etd/article/view/2279>. Acesso em: 16 jul. 2013.

ARAÚJO, Vanessa C. N. Contribuições da metodologia de projetos para o exercício da função de pensar. Dissertação (Mestrado em Educação Tecnológica) - Cefet-MG, Belo Horizonte, 2009.

BARBOSA, A. F. TIC educação 2011: pesquisa sobre o uso das tecnologias de informação e comunicação nas escolas brasileiras. São Paulo: Núcleo de Informação e Coordenação do Ponto Br: Comitê Gestor da Internet no Brasil, 2012.

BARBOSA, E. F.; GONTIJO, A. F.; SANTOS, F. F. Inovações pedagógicas em educação profissional: uma experiência de utilização do MP na formação de competências. Boletim Técnico do Senac, Rio de Janeiro, v. 30, n. 2, maio/ago. 2004.

BLIKSTEIN, P. 0 mito do mau aluno e porque o Brasil pode ser o líder mundial de uma revolução educacional. 25 jul. 2010. Disponível em: <http://www.blikstein.com/paulo/documents/books/ Blikstein-Brasil_pode_ser_lider_mundial_em_educacao.pdf>. Acesso em: 15 jul. 2013.

BONWELL, C. C.; EISON, J. A. Active learning: creating excitement in the classroom. Washington, DC: Eric Digests, 1991. Publication Identifier ED340272. Disponível em: <http://www.eric.ed.gov/PDFS/ED340272. pdf>. Acesso em: 17 jul. 2013.

CALDWELL, B. J.; SPINKS, J. M. Beyond the self-managing school. London: Falmer Press, 1998.

COSTA, A. R. P. Metodologia de projetos: a percepção do aluno sobre os resultados da sua aplicação. Dissertação (Mestrado em Educação Tecnológica) - CEFET-MG, Belo Horizonte, 2010.

FREITAS, F. M. As dimensões da teoria e da prática na formação de profissionais da administração: contribuições da metodologia de projetos à luz do pensamento complexo. Dissertação (Mestrado em Educação Tecnológica) - CEFET-MG, Belo Horizonte, 2003.

GADOTTI, M. História das idéias pedagógicas. 2.ed. São Paulo: Ática, 1994.

GODOY, E. G. U. Contribuições da metodologia de projetos na implantação das tecnologias de informação e comunicação - TIC nos processos educativos da educação básica. Dissertação (Mestrado em Educação Tecnológica) - Cefet-MG, Belo Horizonte, 2009. 
GOLDBERG, D. E. The missing basics \& other philosophical reflections for the transformation of engineering education. PhilSci Archive. [S.I.]: University of Pittsburg, 2010. Disponível em: <http://philsci-archive.pitt. edu/4551/>. Acesso em: 17 jul. 2013.

HERNANDEZ, F.; VENTURA, M.. A organização do currículo por projetos de trabalho. Porto Alegre: Artmed, 1998.

HIGINO, A. F. F. A pedagogia de projetos na educação em ciência \& tecnologia à luz da ciência da complexidade e de uma teoria da negociação: um estudo de caso no ensino da Física dos cursos de Engenharia Industrial do Cefet-MG. Dissertação (Mestrado) - Cefet-MG, Belo Horizonte, 2002.

KNOLL, M. D. The project method: its vocational education origin and development. Journal of Industrial Teacher Education, v. 34, n. 5, Spring 1997. Disponível em: <http://scholar.lib.vt.edu/ejournals/JITE/v34n3/ Knoll.html>. Acesso em: 25 jul. 2004.

LIMA, A. L. D'Império. TIC na educação no Brasil : o acesso vem avançando: e a aprendizagem? In: BARBOSA, Alexandre Fernandes. TIC educação 2011: pesquisa sobre o uso das tecnologias de informação e comunicação nas escolas brasileiras. São Paulo: Núcleo de Informação e Coordenação do Ponto Br: Comitê Gestor da Internet no Brasil, 2012.

MACHADO, L. R. de S. Diferenciais inovadores na formação de professores para a educação profissional. Revista Brasileira de Educação Profissional e Tecnológica, Brasília, DF, v. 1, n. 1, jun. 2008.

MARKHAM, T.; LARMER, J.; RAVITZ, J. Aprendizagem baseada em projetos. Porto Alegre: Artmed, 2008. MEYERS, C.; JONES, Thomas B. Promoting active learning. San Francisco: Jossey Bass, 1993.

MILLER, R.; SHAPIRO, H.; HILDING-HAMANN, K. E. School's over: learning spaces in Europe in 2020: an imagining exercise on the future of learning. [S.I.]: European Commission Joint Research Centre: Institute for Prospective Technological Studies, 2008.

MOURA, D. G. A dimensão lúdica no ensino de ciências. Doutorado (Tese em Educação) - Faculdade de Educação, USP, São Paulo, 1993.

MOURA, D. G.; BARBOSA, E. F. Trabalhando com projetos: planejamento e gestão de projetos educacionais. Petrópolis: Vozes, 2011.

SHAH, S.; NIHALANI, M. Stress free environment in classroom: impact of humor in student satisfaction. Munich: GRIN Publishing, 2012. Disponível em: <http://www.grin.com/en/e-book/192216/stress-freeenvironment-in-classroom-impact-of-humor-in-student-satisfaction\#inside>. Acesso em: 17 jul. 2013.

PECOTCHE, C. B. G. Logosofia: ciência e método. São Paulo: Ed. Logosófica, 2011.

PIRES, A. A. M. Empreendedorismo, protagonismo e pedagogia de projetos: uma simbiose, transdisciplinar. Dissertação (Mestrado em Educação Tecnológica) - Cefet-MG, Belo Horizonte, 2006.

RIBEIRO, R. de C. A aprendizagem baseada em problemas (PBL): uma implementação na educação em engenharia. Tese (Doutorado) - UFSC, Florianópolis, 2005.

SILBERMAN, M. Active learning: 101 strategies do teach any subject. Massachusetts: Ed. Allyn and Bacon, 1996.

UVINHA, R. R.; PEREIRA, D. Metodologias ativas de aprendizagem no ensino de ciências humanas e sociais. ComCiência: revista eletrônica de jornalismo científico, 10 fev. 2010. Disponível em: http://www.comciencia. $\mathrm{br} /$ comciencia $/$ ?section $=8 \&$ edicao $=53 \&$ id $=673$

WANDERLEY, E. C. Feiras de Ciências enquanto espaço pedagógico para aprendizagens múltiplas. Dissertação (Mestrado em Educação Tecnológica) - Cefet-MG, Belo Horizonte, 1999. 